Edu Consilium: Jurnal BK Pendidikan Islam Vol. 3, No. 1, 2022, hlm. 25-37

DOI: $10.19105 /$ ec.v1i1.1808

ISSN 2503-3417 (online)

ISSN 2548-4311 (cetak)

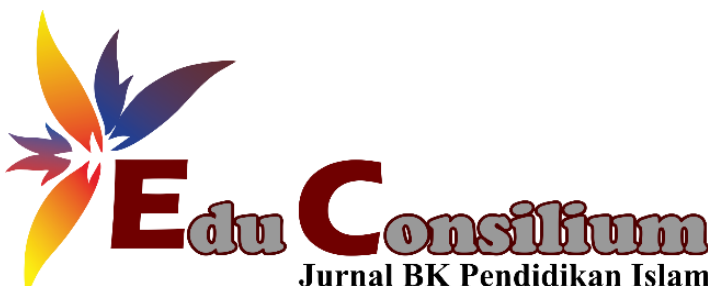

Jurnal BK Pendidikan Islam

\title{
IMPLIKASI TEMBHÂNG MACAPAT MADHURÂ DALAM BIMBINGAN DAN KONSELING
}

\author{
${ }^{1}$ Ayu Raudatul Jannah \\ ${ }^{1}$ Program Studi Magister Bimbingan dan Konseling Universitas Negeri Malang, Indonesia \\ ayuraudatuljannah@gmailcom
}

\begin{abstract}
Progress in all sectors, especially in the field of communication and information can lead to cultural acculturation which has an impact on the identity of the nation's young generation. In this case, sensitivity to the local culture of the nation is needed so that it is able to maintain the character and identity of the nation. The purpose of this study was to examine the implications of tembhâng macapat Madhurâ in Guidance and Counseling. This study used descriptive qualitative method. This research data was collected through a literature review technique which was carried out by collecting text sources or documents in the form of previous research journals that discussed about tembhâng macapat Madhurâ and books about tembhâng macapat Madhurâ as well as in-depth interviews conducted with informants. Data analysis in this study consisted of three stages, namely: (1) data reduction; (2) data presentation; and (3) conclusions or verification. Like Guidance and Counseling which is a medium to help students increase their productivity, tembhâng macapat Madhurâ is a medium used by Madurese elders to convey messages or advice to shape the personality of the Madurese community. Tembhâng macapat Madhurâ contains noble values that are full of relevant moral messages to be used as content in Guidance and Counseling by formulating and internalizing them in Guidance and Counseling services.

Abstrak

Kemajuan diberbagai sektor khsusunya dalam bidang komunikasi dan informasi dapat menimbulkan akulturasi budaya yang berdampak pada jati diri para generasi muda bangsa. Dalam hal ini dibutuhkan kepekaan akan budaya lokal bangsa sehingga mampu mempertahankan karakter dan jati diri bangsa. Tujuan penelitian ini adalah untuk mengkaji implikasi dari tembhâng macapat Madhurâ dalam Bimbingan dan Konseling. Penelitian ini menggunakan metode deskriptif kualitatif. Data penelitian ini dikumpulkan melalui teknik kajian pustaka yang dilakukan dengan mengumpulkan sumber teks atau dokumen berupa jurnal-jurnal penelitian terdahulu yang membahas tentang tembhâng macapat Madhurâ dan buku tentang tembhâng macapat Madhurâ serta wawancara mendalam yang dilakukan kepada narasumber. Analisis data dalam penelitian ini terdiri dari tiga tahap yaitu: (1) reduksi data; (2) penyajian data; dan (3) penarikan kesimpulan atau verifikasi. Sama halnya dengan Bimbingan dan Konseling yang merupakan media untuk membantu siswa untuk meningkatkan produktivitas dirinya, tembhâng macapat Madhurâ merupakan media yang digunakan oleh sesepuh Madura untuk menyampaikan pesan ataupun nasehat untuk membentuk kepribadian masyarakat Madura. Tembhâng macapat Madhurâ mengandung nilai-nilai luhur yang sarat akan pesan moral yang relevan untuk dijadikan sebagai muatan dalam Bimbingan dan Konseling dengan merumuskan dan menginternalisasikannya dalam layanan BK.
\end{abstract}

\section{Kata Kunci:}

Implikasi;

Tembhâng Macapat

Madhurâ;

Bimbingan dan

Konseling.

CEdu Consilium: Jurnal Bimbingan dan Konseling Pendidikan Islam Institut Agama Islam Negeri Madura, Indonesia 


\section{PENDAHULUAN}

Sebagaimana uang logam yang memiliki dua sisi yang saling berkaitan, globalisasi tidak hanya membawa dampak baik namun juga membawa tantangan bagi masyarakat. Perkembangan teknologi komunikasi yang semakin pesat menjadikan akses komunikasi semakin mudah dan cepat, di mana hal tersebut juga membuka kemungkinan adanya interaksi akulturasi yang tidak terbatas. Dalam hal ini anak-anak akan mudah terdoktrin oleh apa yang mereka lihat dan mereka dengar dari televisi maupun internet, yang mana semua itu telah didominasi oleh negara-negara adidaya. Derasnya arus globalisasi berdampak pada karakter dan kepribadian dari para generasi muda. Hal itu nampak dari bagaimana gaya berpakaian, cara bersikap, serta akhlak dan moral dari generasi muda saat ini. Cintokowati (2014) mengungkapkan bahwa dalam pergaulan teman sebaya seringkali ditemukan anak-anak yang saling mengejek bahkan berkata kasar, baik itu di lingkungan sekolah maupun di luar sekolah.

Jika dilihat dari sikap, generasi muda saat ini kurang memiliki sopan santun dan cenderung tidak peduli pada lingkungan sekitarnya. Dilihat dari cara berbahasa, alih-alih menjungjung tinggi bahasa Indonesia, para genersai muda telah mencampurnya dengan bahasa-bahasa di tempat lain, bahkan mereka lebih tertarik dan bangga pada bahasa asing, seperti yang terjadi pada remaja perempuan saat ini yang berlomba-lomba belajar bahasa korea. Dari cara berpakaian, generasi muda saat ini cenderung mengikuti trend dari budaya luar. Tidak jarang kita melihat remaja yang berdandan seperti selebritis bahkan ada yang menggunakan pakaian yang memperlihatkan bagian-bagian tubuhnya yang seharusnya tidak terlihat. Singkatnya mereka lebih senang menjadi orang lain dan menutupi identitasnya sendiri.

Selain itu selama tahun 2021 Komisi Perlindungan Anak Indonesia (KPAI) telah mencatat adanya kasus perundungan serta tawuran pelajar di satuan pendidikan. Terdapat satu kasus terkait kasus perundungan atau kasus kekerasan berupa kasus kekerasan berbasis SARA (Suku. Agama, dan Ras), kasus perundungan atau pembullyan sebanyak enam kasus, dan sepuluh kasus terkait tawuran antar pelajar. Berdasarkan studi pendahuluan yang dilakukan oleh peneliti melalui wawancara dengan salah satu siswa SMA Negeri 1 Pamekasan diperoleh bahwa fenomena bullying merupakan suatu hal yang kerap terjadi di kelasnya, terlebih saat awal masuk SMA. Pelaku bullying biasanya adalah siswa-siswa yang mengklaim dirinya sebagai siswa populer dan tentu saja yang menjadi korban bullying adalah siswa-siswa yang terisolir di kelasnya. 
Pendidikan merupakan wadah dalam membentuk kepribadian. Pendidikan memiliki peranan dalam mentransfer nilai-nilai budaya untuk mengimbangi pesatnya kemajuan zaman sehingga para generasi muda mampu untuk memahami kebudayaannya sendiri untuk kemudian dijadikan sebagai pedoman hidup. Sebagaiana yang diungkapkan oleh Gumilang (2017), bahwa nilai-nilai budaya luhur dapat dilestarikan dengan cara mewariskannya kepada generasi muda melalui pendidikan, baik itu pendidikan formal, informal, maupun nonformal. Bimbingan dan Konseling selaku bagian dari pendidikan memiliki peranan dalam memastikan tidak terjadi benturan nilai-nilai antara identitas lokal dan identitas yang lain yang mengakibatkan para generasi muda kehilangan identitasnya. Oleh karena itu Bimbingan dan Konseling harus mampu berdedikasi dalam menjaga serta memupuk kesadaran terhadap budaya bangsa sebagai upaya dalam mengelola identitas generasi muda bangsa.

Dari fenomena-fenomena tersebut para pendidik perlu meningkatkan perannya dalam proses pendidikan termasuk dalam Bimbingan dan Konseling. Bimbingan dan Konseling harus mampu memposisikan dirinya sebagai pemeran utama dalam mempertahankan jati diri para generasi muda. Dalam hal ini Bimbingan dan Konseling harus mampu merumuskan nilai-nilai budaya bangsa ke dalam layanan BK sebagai upaya untuk membangun prinsip dan nilai-nilai bangsa serta mencegah nilai-nilai negatif dari budaya luar di kalangan siswa. Namun sayangnya dari hasil observasi dan wawancara yang peneliti lakukan diperoleh bahwa sejauh ini guru BK masih menggunakan metode konvensional (ceramah) dalam memberikan layanan BK dan belum ada inovasi terkait pemberian layanan tersebut. Hal tersebut dikarenakan kurangnya pemahaman mereka terkait Bimbingan dan Konseling berbasis kearifan lokal.

Setiap daerah di Indonesia memiliki kebudayaan masing-masing. Orang Manado memiliki kolintang, orang Bali memiliki janger, orang Sunda memiliki calung, dan orang Minangkabau memiliki randai. Kebudayaan-kebudayaan tersebut masih dirawat dan dilestarikan sampai saat ini sehingga tetap dapat dinikmati dalam kehidupan sehari-hari. Di Madura sendiri kebudayaan yang tetap dirawat dan dilaksanakan sampai saat ini di antaranya adalah kerapan sapi, rokat tasè', upacara nadar, penca', dan lainnya. Sedangkan kebudayaan seperti topeng dan pujian-pujian sudah mulai jarang dilaksanakan. Selain itu kebudayaan Madura yang mulai terabai keberadaannya adalah tembhâng macapat atau yang disebut juga dengan mamaca.

Pada zaman dulu tembhâng macapat berupa pembacaan nasehat baik atau cerita yang berisi tauladan yang disampaikan dengan cara ditembangkan. Tembhâng macapat biasanya 
ditulis oleh orang-orang yang halus budi pekertinya serta menjunjung tinggi etika dan moral, karena itulah setiap tembhâng yang mereka tulis merupakan mustika dalam kehidupan yakni petutur agar hidup bahagia di dunia dan akhirat. Bagi orang zaman dulu, tembhâng macapat merupakan kesenangan yang utama, sebab selain nyaman didengar juga dapat menghilangkan kesusahan serta membuka wawasan. Selain itu tembhâng macapat biasanya juga dipakai untuk oghem (meramal) yang dilakukan dengan cara menafsirkan isi pada halaman layang yang telah dipilih sebelumnya. Pada umumnya, setelah seseorang melakukan oghem, maka mereka cenderung akan ada perubahan pada orang tersebut, yakni menjadi lebih baik dari sebelumnya.

Tembang macapat memang berasal dari Jawa, namun para leluhur Madura telah mengadopsinya dan disesuaikan dengan karakter Madura yang kemudian menjadi bagian dari kekayaan budaya Madura yang sarat akan pesan dan nilai moral yang tinggi. Selain memuat aspek tontonan, tembang macapat juga memuat aspek tuntunan dan tatanan. Sebagai tuntunan, macapat berisi nilai-nilai budi pekerti yang syarat akan pesan moral. Selain itu tuntunan dalam macapat juga memuat pengetahuan mengenai siklus kehidupan manusia. Sedangkan sebagai tatanan macapat dimaksudkan untuk menata kehidupan dalam bermasayarakat yang mana hal itu dapat berlaku dengan baik apabila nilai-nilai luhur yang terkandung dalam macapat sudah dapat dipahami dan dilaksanakan dalam kehidupan seharihari sehingga memberikan hasil yang positif dalam tatanan masyarakat, bangsa, negara. (Santosa, 2016; Dana dan Kusmiyati, 2018).

Keberadaan tembhâng macapat Madhurâ yang sudah asing dikalangan generasi muda akibat tergeser oleh kebudayaan-kebudayaan barat dapat dijadikan sebagai muatan dalam Bimbingan dan Konseling. Nilai-nilai adiluhung yang termuat dalam tembhâng macapat Madhurâ merupakan nilai-nilai yang dibutuhkan oleh siswa untuk menjaga dirinya, mempertahankan kondisi kondusif dalam dirinya, serta meningkatkan produktivitas dirinya. Dengan demikian guru Bimbingan dan Konseling dapat merumuskan dan menginternalisasikan nilai-nilai dalam tembhâng macapat Madhurâ dalam pemberian layanan BK. Penggunaan tembhâng macapat Madhurâ sebagai muatan dalam Bimbingan dan Konseling juga menjadi salah satu bentuk kontribusi dari Bimbingan dan Konseling dalam melastarikan budaya lokal yang mulai hilang. Berdasarkan deskripsi di atas, maka penelitian ini akan mengkaji implikasi tembhâng macapat Madhurâ dalam Bimbingan dan Konseling. 


\section{METODE}

Dalam penelitian ini, pendekatan penelitian yang digunakan adalah penelitian kualitatif. Penelitian kualitatif adalah penelitian yang ditujukan untuk mendeskripsikan dan menganalisis fenomena, peristiwa, aktivitas sosial, sikap kepercayaan, persepsi, pemikiran orang secara individual maupun kelompok (Moleong, 2007). Jenis pendekatan penelitian ini dipaparkan secara deskriptif. Jenis penelitian deskriptif kualitatif yang digunakan pada penelitian ini dimaksudkan untuk memaparkan implikasi tembhâng macapat Madhurâ dalam Bimbingan dan Konseling. Data penelitian ini dikumpulkan melalui teknik kajian pustaka yang dilakukan dengan mengumpulkan data-data dari sumber teks atau dokumen seperti buku tentang tembhâng macapat Madhurâ dan jurnal-jurnal penelitian terdahulu yang membahas tentang tembhâng macapat Madhurâ. Data penelitian juga diperoleh dari wawancara mendalam (in depth interview) kepada dua narasumber, yaitu anggota pakem maddhu yang pernah melakukan penelitian terkait nilai-nilai dalam tembhâng macapat Madhurâ dan guru Bahasa Madura. Analisis data dalam penelitian ini mencakup tiga tahap, yaitu: (1) reduksi data, dalam hal ini peneliti mengumpulkan serta mencatat data-data yang berkaitan dengan tembhâng macapat Madhurâ yang diperoleh dari buku, jurnal, artikel serta wawancara dengan narasumber; (2) penyajian data, dalam hal ini peneliti menyusun dan mengaktegorisasikan data mengenai nilai-nilai yang terkandung dalam tembhâng macapat Madhurâ; dan (3) penarikan kesimpulan/verifikasi.

\section{HASIL}

\section{Tembhâng Macapat Madhurâ}

Tembhâng macapat Madhurâ merupakan salah satu budaya lokal yang sarat akan pesan moral dan budi pekerti. Tembhâng macapat Madhurâ mengandung makna simbolik, yakni hubungan manusia dengan manusia, hubungan manusia dengan alam, dan hubungan manusia dengan Tuhannya. Tembhâng macapat Madhurâ berisi nasihat baik itu tentang ketakwaan maupun tentang keselamatan. Tembhâng macapat Madhurâ terdiri atas 9 jenis, yakni: (1) tembhâng artatè; (2) tembhâng dhurma; (3) tembhâng kenantè (salangèt); (4) tembhâng maskumambang; (5) tembhâng kasmaran; (6) tembhâng mèjhil; (7) tembhâng pangkor; (8) tembhâng sènom; dan (9) tembhâng pucung.

Masing-masing dari tembhâng macapat Madhurâ memiliki watak yang berbeda. Penggunaannyapun haruslah sesuai dengan keadaan ataupun kondisi saat ini serta cerita yang 
akan dibawakan. Masing-masing watak dari tembhâng macapat Madhurâ adalah sebagai berikut.

1. Tembhâng artatè berarti pengahrapan yang manis. Watak dari tembhâng artatè adalah gemulai atau manis. Biasanya digunakan sebagai pembuka (prolog) dalam cerita.

2. Tembhâng dhurma memiliki arti macan. Watak dati tembhâng dhurma ini adalah sedih. Biasanya digunakan dalam situasi atau kondisi perang.

3. Tembhâng kenantè (salangèt) artinya dekat dan biasanya digunakan dalam nasehat tentang kerukunan.

4. Tembhâng maskumambang memiliki arti prihatin atau sangat susah.

5. Tembhâng kasmaran memiliki makna heran.

6. Tembhâng mèjhil memiliki arti keluar. Tembhâng mèjhil ini biasanya digunakan dalam menghadapi pertikaian atau kesusahan.

7. Tembhâng pangkor memiliki arti ekor dan biasanya tembhâng pangkor ini digunakan ketika menghadapi perang.

8. Tembhâng sènom artinya daun asam yang muda. Biasanya digunakan dalam nasehat yang berisi banyak kiasan.

9. Tembhâng pucung artinya perumpaan dan biasanya digunakan dalam tebak-tebakan.

Tabel 1. Contoh Tembhâng Macapat Madhurâ

\begin{tabular}{|c|c|}
\hline $\begin{array}{c}\text { TEMBHÂNG MACAPAT } \\
\text { MADHURÂA }\end{array}$ & MAKNA \\
\hline \multicolumn{2}{|c|}{ Tembhâng Artatè } \\
\hline $\begin{array}{l}\text { Aḍu ana' maju bi' kènga'è } \\
\text { Dhâdhâbuna orèng towa-towa } \\
\text { Rajhut jhuko' ghun è tasè '’ } \\
\text { Jhilâ rè lemmes ongghu } \\
\text { Ghula annyong ghâmpang paghuli } \\
\text { Li-bâli ta' katara } \\
\text { Mèla jâgâ ongghu } \\
\text { Brâkay ghâlâk ghun mowara } \\
\text { Bhâbhâjâna taḍ̂a' kenning anḍiaghin } \\
\text { Dhumèn klèro terghâ' na }\end{array}$ & $\begin{array}{l}\text { Berisi nasehat untuk menjaga perilaku } \\
\text { dan ucapan kita }\end{array}$ \\
\hline \multicolumn{2}{|c|}{ Tembhâng Dhurma } \\
\hline
\end{tabular}


Lamon dhika è pasraè pangghâbâyân

Ampon marè apèkkèr

Terrang ka'ekko'na

Ajhânjhi maranta'a

Pon pon brinto tarongghuwi

Angghâp tangghungan

$M a$ ' ta' malo dâ' orèng
Berisi nasehat untuk bertanggungjawab atas tugas dan kewajiban kita

\section{Tembhâng Pangkor}

Orèng tokang ghâbây brangka

Ajjhâ' lèbur bhâdhâna ghi matèngghi

Dấ' orèng sèra'a saos

Perrèng engghun tennonan

Parjhughâna dhika kodhu anḍhâp asor

Bengko bhâghus klèngghin rajâ

Jhâ' makaton abâ' lebbi
Berisi nasehat untuk tidak sombong dan bersikap sopan santun

Tembhâng Mèjhil

Poma-poma jhâ' sampè kloppaèn

Berisi nasehat tentang cara berperilaku,

Monyèna pètotor adab, dan sopan santun ketika

Rèng satrèya tor aghung nyamaèn

Tao tata jhâtmèkana buddhi berkumpul ataupun berinterakasi

Olat pancer manes

Ė̀imma'a engghun dengan orang lain

\section{Tembhâng Kasmaran}

Nyatana sè daddhiaghin

Kakorangan kasennengngan

Bâdâ è abâ'na dhibhi'

Sè sapèsan kakarebbhân

Kareb ta' dhuli tekka

Salanjhângnga pèkkèr ongghu

Nyarè akkal sè kollèa
Berisi nasehat untuk bekerja keras namun tetap harus mawas diri

\section{Tembhâng Sènom}

Pra kanca kaulâ sadhâjâ

Dhâbek bi' ongghu kèngaè

Berisi nasehat untuk menepati janji

Laddhing ghun sokona ajâm

Jhin-jhânjhin jhâ' èntèngaghin

Ghâmparan dâri kolè'

Bi' sompa pan papaḍ̂ saos

Dhâbuna bângatowa

Ghângan ghâtèl ghâghâng paḍi

Èkapetteng ḍ̂' 'ka iman ka dhâddhinna

\section{Tembhâng Kenantè (Salangèt)}


Rampa' naong bâringin korong

Parèbhâsan ngoca'aghi

Pan ngaobhi kaḍhâng bârghâ

Dhâk-ondhâk aropa perrèng

Ta'ghâmpang napso aghuḍ̂a

Napso jhubâ' pama'aghi

\section{Tembhâng Maskumambang}

Aộ ana' kènga 'ana ongghu atè

Jhujhur rèya moljâ

Dâ' bhâdhân ta' aberrâ'i

La-mala dhâmmang kèbâna
Berisi nasehat untuk hidup rukun dan damai, peduli pada orang lain, saling mengayomi, dan mengontrol hawa nafsu yang dapat membawa petaka

\section{Tembhâng Pucung}

Kerras lamon ta' akerrès rogi ongghu Tanto nemmo palang

Berisi nasehat untuk senantiasa berhati-

Ngaddhu bângal ta' papèkkèr hati dan berpikir sebelum mertidak

Paḍ̂̂na aperrang ta 'ngèbâ ghâghâman atau melakukan sesuatu agar tidak menyesal kemudian 
33 Edu Consilium: Jurnal BK Pendidikan Islam, Vol. 3, No. 1, Februari, 2022

Nilai-nilai Tembhâng Macapat Madhurâ dalam Bimbingan dan Konseling

Tabel 2. Nilai-nilai yang Terkandung dalam Tembhâng Macapat Madhurâ dan Kaitannya dengan Bimbingan dan Konseling

\begin{tabular}{|c|c|c|c|c|}
\hline $\begin{array}{c}\text { Tembhâng macapat } \\
\text { Madhurâ }\end{array}$ & Makna & $\begin{array}{c}\text { Tugas Perkembangan } \\
\text { Peserta Didik }\end{array}$ & $\begin{array}{c}\text { Standar Kompetensi } \\
\text { Kemandirian Peserta Didik }\end{array}$ & $\begin{array}{c}\text { Bidang Bimbingan } \\
\text { dan Konseling }\end{array}$ \\
\hline Tembhâng artatè & Menjaga lisan & \multirow{9}{*}{ 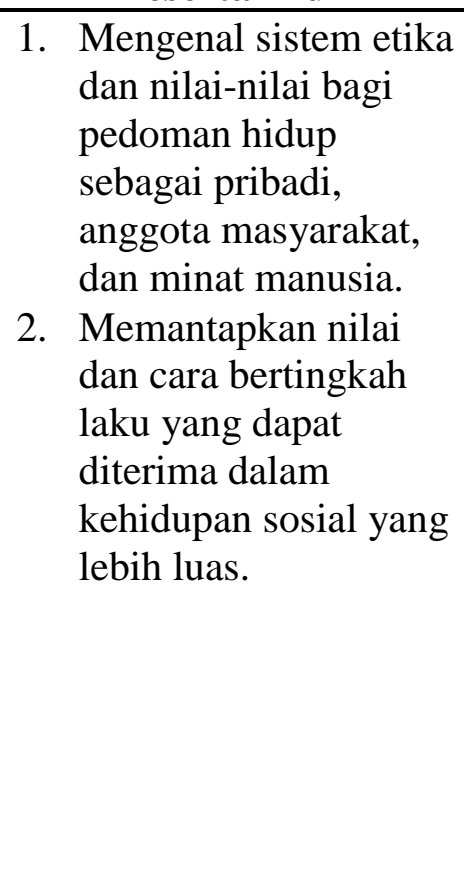 } & \multirow{9}{*}{$\begin{array}{ll}\text { 1. Landasan perilaku etis } \\
\text { 2. Kesadaran tanggungjawab } \\
\text { sosial }\end{array}$} & \multirow{9}{*}{$\begin{array}{l}\text { 1. Bidang pribadi } \\
\text { 2. Bidang sosial }\end{array}$} \\
\hline Tembhâng dhurma & Bertanggungjawab & & & \\
\hline $\begin{array}{l}\text { Tembhâng kenantè } \\
\text { (salangèt) }\end{array}$ & $\begin{array}{l}\text { Kerukunan } \\
\text { Cinta damai } \\
\text { Tolong menolong }\end{array}$ & & & \\
\hline Tembhâng kasmaran & $\begin{array}{l}\text { Kerukunan } \\
\text { Tolong menolong }\end{array}$ & & & \\
\hline $\begin{array}{l}\text { Tembhâng } \\
\text { Maskumambang }\end{array}$ & Kejujuran & & & \\
\hline Tembhâng Mèjhil & $\begin{array}{l}\text { Bersikap sopan } \\
\text { santun }\end{array}$ & & & \\
\hline Tembhâng Pangkor & $\begin{array}{l}\text { Tidak sombong } \\
\text { Bersikap sopan } \\
\text { santun }\end{array}$ & & & \\
\hline Tembhâng Sènom & $\begin{array}{l}\text { Menepati janji } \\
\text { Bertanggungjawab }\end{array}$ & & & \\
\hline Tembhâng pucung & $\begin{array}{l}\text { Berpikir rasional } \\
\text { Teliti }\end{array}$ & & & \\
\hline
\end{tabular}




\section{PEMBAHASAN}

Tembhâng Macapat Madhurâ merupakan salah satu khazanah budaya Madura berupa tradisi lisan dalam bentuk puisi Madura kuno yang sarat akan pesan moral yang tinggi. Tembhâng macapat Madhurâ bukan hanya sekedar kesenian yang menyuguhkan nilai estetika semata namun juga merupakan media dalam menyampaikan pesan ataupun nasehat. Sebagian masyarakat Madura bahkan menggunakan tembhâng macapat untuk oghem, yang mana hal itu bertujuan untuk memperbaiki diri serta meningkatkan kapastitas diri. Melalui syair-syair dalam tembhâng macapat Madhurâ inilah sesepuh Madura membentuk kepribadian masyarakat Madura. Syaifuddin (2011), mengungkapkan bahwa dalam tembhâng sènom terdapat anjuran kepada masyarakat untuk menjaga dan menjunjung kerukunan hidup dalam bersaudara sedangkan dalam tembhâng mèjhil berisi peringatan kepada kita agar tidak sombong terhadap masyarakat sekitar walaupun memiliki pengetahuan yang luas serta mengingatkan jangan sampai melupakan dan meninggalkan kewajiban. Selain itu Nur Aini (2013) dalam penelitiannya menyimpulkan bahwa nilai-nilai moral yang terkandung dalam tembhâng macapat Madura adalah: (a) hubungan manusia terhadap Tuhannya yang meliputi sholat dan do'a; (b) hubungan manusia terhadap dirinya yang meliputi tatakrama dan melaksanakan norma yang ada; dan (c) hubungan anak terhadap orangtuanya meliputi berbakti dan melaksanakan segala perintahnya.

Sama halnya dengan tembhâng macapat Madhurâ, Bimbingan dan Konseling juga merupakan media dalam membantu siswa sehingga dapat mengembangkan potensi dirinya secara maksimal. Dalam hal ini Guru Bimbingan dan Konseling memiliki alat untuk mengembangkan potensi yang ada dalam diri siswa yang terwujud melalui berbagai jenis layanan BK yang memiliki berbagai fungsi di antaranya fungsi pemahaman, pencegahan, pengentasan, pemeliharaan, serta pengembangan. Menurut Muslihati (2019), layanan BK dapat dialokasikan melalui pendekatan individual yang mencakup konseling individu dan konsultasi ataupun pendekatan kelompok yang mencakup konseling kelompok, bimbingan kelompok, serta bimbingan klasikal.

Mengingat bahwa tembhâng macapat Madhurâ sarat akan nilai-nilai kehidupan dan pesan moral maka perlu digarisbawahi bahwa pelestarian tembhâng macapat Madhurâ sangat penting bagi generasi muda. Tembhâng macapat Madhurâ dipandang perlu untuk diaktualisasikan dalam kehidupan para generasi muda. Nilai-nilai yang terkandung dalam tembhâng macapat Madhurâ juga relevan untuk diinternalisasikan dalam Bimbingan dan Konseling untuk membantu siswa dalam mempertahankan kondisi kondusif dalam dirinya serta meningkatkan produktivitas dirinya. Dalam hal ini, guru Bimbingan dan Konseling 
dapat memanfaatkan tembhâng macapat Madhurâ sebagai muatan dalam pemberian layanan BK. Seperti halnya penelitian yang dilakukan Sani (2019), tentang "keefektifan tembang macapat pangkur untuk mereduksilam perilaku agresif siswa kelas VIII SMP Negeri 1 Ceper tahun ajaran 2018/2019" yang menunjukkan bahwa pemeberian layanan BK menggunakan tembang macapat pangkur efektif untuk mereduksi perilaku agresif siswa kelas VIII SMP Negeri 1 Ceper. Selain itu penelitian yang dilakukan oleh Sutarno \& Barida (2017) tentang "kajian bahan Bimbingan dan Konseling dalam serat wedhatama" menunjukkan bahwa serat wedhatama yang memuat 100 bait tembang macapat yang terdiri atas pupuh-pupuh pangkur, sinom, pocung, gambuh, dan kinanti layak dan dapat dijadikan sebagai sumber bahan dalam layanan informasi dan tampilan pustaka dalam layanan BK bagi siswa di jalur pendidikan formal.

Dalam hal ini guru Bimbingan dan Konseling juga dapat mengalokasikannya sebagai muatan dalam layanan BK dengan pendekatan kelompok. Melalui layanan kelompok siswa secara bersama-sama dapat memperoleh berbagai bahan dari narasumber (terutama dari guru Bimbingan dan Konseling) yang bermanfaat untuk kehidupan sehari-hari baik sebagai individu maupun sebagai pelajar, anggota keluarga, dan masyarakat (Sukardi, 2003). Sebagaimana penelitaian yang dilakukan oleh Edmawati (2021) tentang "keefektifan konseling kelompok berbasis kearifan lokal tembang macapat sinom untuk meningkatkan resiliensi generasi Z" yang menunjukkan bahwa konseling kelompok berbasis kearifan lokal tembang macapat sinom yang kaya akan falsafal kehidupan efektif untuk meningkatkan resiliensi generasi Z. Guru Bimbingan dan Konseling juga dapat merumuskan dan menginternalisasikan ttembhâng macapat Madhurâ dalam layanan bimbingan kelompok. Dalam hal ini pelaksanaan bimbingan kelompok haruslah disusun sedemikian rupa sehingga tujuan dari bimbingan kelompok dapat tercapai. Metode atau teknik yang digunakan dalam bimbingan kelompok juga tidak terlepas dari kepribadian guru Bimbingan dan Konseling. Untuk itu dalam menginternalisasikannya guru Bimbingan dan Konseling harus mampu mengembangkan metode atu tenik dalam bimbingan kelompok dengan tepat sehingga nantinya dapat menumbuhkan ketertarikan dari siswa.

Siswa cenderung akan merasa senang dan mudah mengingat apa yang mereka pelajari ketika guru Bimbingan dan Konseling mengajarkan keterampilan sosial dengan cara bermain peran. Sebagaimana yang diungkapkan oleh Erford (2017), bahwa melalui permainan peran siswa dapat mempelajari keterampilan baru dari perilaku-perilaku yang diperankan serta bagaimana pengaruh dari perilaku tersebut terhadap orang lain. Selain itu guru Bimbingan 
dan Konseling juga harus mampu menguasai materi bimbingan karena inti dari kegiatan bimbingan kelompok ini adalah penyampaian informasi untuk membantu siswa dalam merubah persepsinya (Erford, 2010). Oleh karena itu penting kiranya guru Bimbingan dan Konseling memiliki pengetahuan dasar tentang nilai-nilai budaya lokal yang akan diinternalisasikan kepada siswa.

Melalui internalisasi nilai-nilai yang terkandung dalam tembhâng macapat Madhurâ diharapkan upaya mempertahankan jati diri bangsa dari para generasi muda sekaligus usaha pelestarian tembhâng macapat Madhurâ dapat berlangsung dengan baik. Dengan demikian pada akhirnya diharapkan anak-anak dapat mengembangkan potensi yang ada dalam dirinya dan tumbuh menjadi manusia yang berbudaya, memiliki wawasan yang luas, mampu mengaktualisasi potensi dirinya, mengekspresikan pikiran dan perasaannya, serta memiliki karakter yang kuat sehingga mampu mempertahankan jati diri bangsa di tengah perkembangan zaman.

\section{SIMPULAN}

Seperti halnya Bimbingan dan Konseling yang merupakan media untuk membantu siswa agar dapat meningkatkan produktivitas serta mengoptimalkan potensi yang ada dalam dirinya, tembhâng macapat Madhurâ merupakan media yang digunakan oleh sesepuh Madura untuk menyampaikan pesan ataupun nasehat untuk membentuk kepribadian masyarakat Madura. Nilai-nilai dala tembhâng macapat Madhurâ mencakup hubungan manusia dengan Tuhannya, hubungan manusia dengan dirinya, serta hubungan manusia dengan lingkungannya (orang tua, masyarakat). Tembhâng macapat Madhurâ dapat dijadikan sebagai muatan atau sumber bahan dalam Bimbingan dan Konseling. Guru Bimbingan dan Konseling dapat merumuskan dan menginternalisasikannya dalam layanan BK baik itu melalui pendekatan individual maupun pendekatan kelompok.

\section{DAFTAR RUJUKAN}

Agustin, Dyah Satya Yoga. 2011. Penurunan Rasa Cinta Budaya dan Nasionalisme Generasi Muda Akibat Globalisasi. Jurnal Sosial Humaniora, 4 (2), 177-185.

Aini, Nur. 2014. Analisis Nilai-Nilai Moral dalam Tembang Macapat Madura di Desa Legung Timur Batang-Batang Sumenep. Skripsi. STKIP PGRI Sumenep.

Cintokowati, Iyut., Siti S. Fadhilah, dan Wardatul Djannah. 2014. Keefektifan Layanan Bimbingan Kelompok dengan Sosiodrama untuk Meningkatkan Sopan Santun pada Peserta Didik Kelas VIII SMP Negeri 14 Surakarta Tahun 2013/2014. Jurnal Hasil Riset, 1-12. 
Dana, I Wayan dan A.M. Hermien Kusmayati. 2018. H. Sastro sebagai Penggerak Mamaca di Pamekasan Madura. Resital 19 (2), 89-94.

Edmawati, Mahmuddah Dewi. 2021. Keefektifan Konseling Kelompok Berbasis Kearifan Lokal Tembang Macapat Sinom untuk Meningkatkan Resiliensi Generasi Z. Counsellia: Jurnal Bimbingan dan Konseling 11 (2), 143-156.

Effendy, Moh Hafid. 2021. Nilai Religius pada Kearifan Lokal Tembang Macapat Madura. Khazanah Theologia 3 (1), 1-12.

Effendy, Moh. Hafid. 2015. Local Wisdom dalam Tembang Macapat Madura. OKARA, Vol. 1, Tahun X, 55-72.

Erford, Bradley. T. 2010. Group Work in The Schools. Boston: Pearson.

Erford, Bradley. T. 2017. 40 Teknik yang Harus Diketahui setiap Konselor. Jogjakarta: Pustaka Pelajar.

Gumilang, Galang Surya. 2017. Internalization of Philosophical Value "Tembang Macapat" in Guidance and Counseling. Prosiding SNBK (Seminar Nasional Bimbingan dan Konseling) 1 (1), 62-77.

Moleong, Lexy J. 2007. Metodologi Penelitian Kualitatif. Bandung: PT Remaja Rosda Karya.

Muslihati. 2019. Peran Bimbingan dan Konseling dalam Penguatan Pendidikan Karakter di Sekolah Menengah Kejuruan. Jurnal Kajian Bimbingan dan Konseling. 4 (3), 101108.

Panduan Operasional Penyelenggaraan Bimbingan dan Konseling Sekolah Menengah Atas (SMA). 2016. Kementerian Pendidikan dan Kebudayaan Direktorat Jenderal Guru dan Tenaga Kependidikan.

Ramlah. 2018. Pentingnya Layanan Bimbingan Konseling bagi Peserta Didik. Jurnal AlMau'izhah 1 (1), 70-76.

Sani, Monica. 2019. Keefektifan Tembang Macapat Pangkur untuk Mereduksi Perilaku Agresif Siswa Kelas VIII SMP Negeri 1 Ceper Tahun Ajaran 2018/2019. Skripsi. Universitas Sebelas Maret Surakarta.

Santosa, Puji. 2016. Fungsi Sosial Kemasyarakatan Tembang Macapat. Widyaparwa 44 (2), 97-109.

Sastrodiwirjo, Oemar. 2008. Tembhâng Macapat Madhurâ. Surabaya: Karunia.

Sukardi, Dewa Ketut. 2003. Manajemen Bimbingan dan Konseling di Sekolah. Bandung: Alfabeta.

Susanto, Edi. 2016. Tembhâng Macapat Madura: Perspektif Sosiologi Pengetahuan. Nuansa 13 (1), 206-230.

Sutarno, S dan Muya Barida. 2017. Kajian Bahan Bimbingan dan Konseling dalam Serat Wedhatama. Jurnal Kanjian Bimbingan dan Konseling 2 (3), 114-122.

Syafiuddin. 2011. Nilai-nilai Religius dalam Antologi Tembang Macapat Madura Karya Oemar Sartrodiwiryo. Pamekasan: Universitas Madura.

Wahyudi, Syaiful Arif dan Rini Eka Setyawati. 2017. Pembelajaran Macapat sebagai Upaya Melestarikan Kearifan Lokal Madura. Prosiding Seminar Nasional Bahasa dan Sastra Indonesia dalam Konteks Global. 